EESTI NSV TEADUSTE AKADEEMIA TOIMETISED. 19. KÖIDE KEEMIA * GEOLOOGIA. 1970, Nr. 1

ИЗВЕСТИЯ АКАДЕМИИ НАУК ЭСТОНСКОЙ ССР. ТОМ 19 ХИМИЯ * ГЕОЛОГИЯ. 1970, № 1

\title{
ИЗМЕНЧИВОСТЬ И ТАКСОНОМИЧЕСКОЕ ПОЛОЖЕНИЕ ANGOPORA HISINGERI (JONES)
}

В 1930 г. из верхних мергелей Висбю о. Готланд О. Джонсом (Jones, 1930) был установлен новый род табулят - Laminopora, отнесенный нм на основании шиповатых септальных ребер к тециидам. В дальнейшем (Jones, 1936) род был переименован в Angopora, поскольку название «Laminopora» оказалось оккупированным Ж. Михелином для рода мшанск из отряда Cheilostomata.

Ввиду негілноты первоописания, не раскрывающего всего разнообразия стенок, соединительных и септальных образований, а также из-за небольшого увеличения приведенных О. Джонсом изображений, морфология этого монотипического рода до сих пор недостаточно известна, и этс является основной причиной расхождений в определении таксономической принадлежности Angopora. В советской палеонтологической литературе данный род, согласно взглядам его автора, рассматривался как самостоятельный род семейства Theciidae (Соколов, 1955, 1962; Клааманн, 1964), в зарубежной - как синоним рода Thecia Goldfuss (Lang, Smith, Thomas, 1940; Hill, Stumm, 1956). В самое последнее время А. Стасинской (Stasinska, 1967) выдвинута еще третья точка зрения, согласно которой Angopora выводится из тециид и объединяется с новым родом Kiaerites в новое семейсгво Angoporidae внутри подотряда Favositina.

В связи с неопределенностью в толковании о таксономической прннадлежности рода Angopora, могут представлять интерес результаты исследования его типового вида Angopora hisingeri (Jones), позволяющие расширить представления о пределах изменчивости отдельных признаков этого вида и сделать некоторые выводы относительно таксономнческого положения рода.

Автор искренне признателен д-ру В. Яануссону (Государственный музей истории природы, Стокгольм) за предоставленный ценный материал, большая часть которого собрана им самим из разных местонахождений нижних и верхних мергелей Висбю, в том числе и из типового местонахождения - клифа Хёгклинт.

Поли пн я к и Angopora hisingeri имеют неправильную форму, вх максимальный диаметр колеблется от 40 до 120 мм. Толщина корок сравнительно выдержанная: 25-30 мм в центральной части полипняка, а у краев уменьшается до 20-10 м.. Поверхность колонии почти никогда не бывает ровной - ей свойственны невысокие бугорки или удлиненные вздутия. Относительная высота поднятых участков не превышает 510 мм, диаметр бугорков также выдерживается в том же интервале и редко доходит до 25 м.м. 
Кор аллиты - призматические, средних размеров, имеют свойственную для плоских полипняков ориентировку, т. е. стелются в самом основании колонии, а затем быстро выпрямляются. Среди нормально развитых преобладают кораллиты диаметром 1,1-1,6 мм (рис. 1), причем

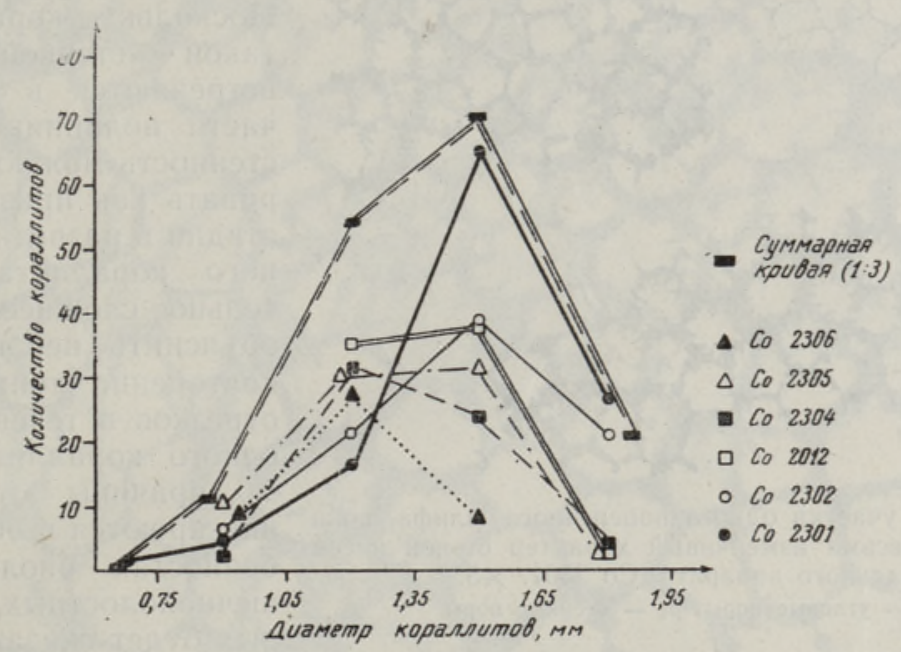

Рис. 1. Распределение в некоторых колониях Angopora hisingeri диаметра кораллитов по классам: $<0,75$; $0,75-1,05$; $1,05-1,35 ; 1,35-1,65 ; 1,65-1,95$.

Со 2301 и Со 2302 - карьер цементной фабрнки Висбю; верхний лландовери, нижние мергели Висбю. Со 2012 - южный холм близ Снэкгордбадена, Со 2304 - Корпклинт, Со 2305 - южнее аэропорта Висбю, Со 2306 - Хёгклинт - все из верхних мергелей Висбю.

в зависимости от геологического возраста экземпляров доминирующие циаметры несколько различны. Так, в нижних мергелях Висбю сильно преобладают диаметры $1,2-1,6$ мм, а в верхних - 1,2-1,5 мм. Количество кораллитов диаметром менее 1,1 мм невелико. Это позволяет рассматривать кораллить с поперечником 1,1 мм и выше как характерные для взрослой стадии данного вида. Исключение составляют скопления явно взрослых, но захиревших кораллитов, наблюдаемые в некоторых участках полипняков, менее благоприятных для поступления пищи (например, пониженные участки поверхности полипняков). Здесь кораллиты, кроме более мелких размеров, могут иметь в поперечном разрезе также сдавленный габитус (табл. II, фиг. 3). Кораллиты диаметром 1,7 м.и н более наблюдаются не во всех полипняках, в значительном количестве они пока обнаружены в нижних мергелях Висбю (рис. 1, Со 2301 и Со 2302). Некоторое увеличение числа кораллитов более крупного диаметра может быть объяснено местными экологическими особенностями. Максимальный интервал изменчивости кораллитов по имеющемуся материалу - 0,5-1,9 мм.

С тенки и септальны й аппа р ат обнаруживают весьма широкую изменчивость, причем морфология стенок находится в прямой зависимости от степени развития септальных образований.

В предєлах колонии нередки участки с четкими пента- или гексагональными кораллитами, имеющими прямые тонкие стенки $(0,04-0,1$ ми) и лишь единичные короткие септальные шипики. В этих участках кораллиты Angopora с трудом отличимы от кораллитов представителей Favosites (рие. $2, A$ ). Некоторым отличием первых являются зернистая микроструктура стенок и слабо развитый межстенный шов. Последний или 


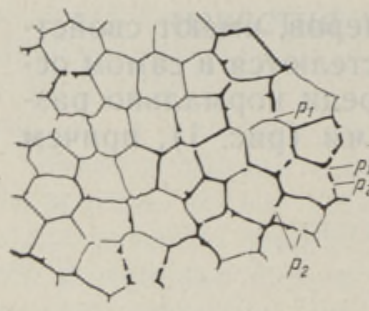

A

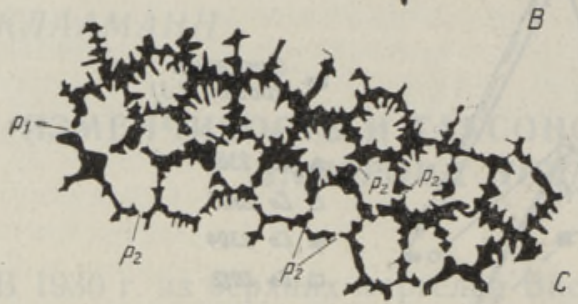

Рис. 2. Три участка одного поперечного шлифа, пока зывающие весьма изменчивый характер стенок и септального аппарата. Со 2301. $\times 5$.

$p_{1}$ - угловые поры; $p_{2}-$ стенные поры. совершенно незаметен, или появляется только в виде тонкой прерывистой линин, а еще реже - как светлая точечная линия. Поскольку кораллиты с такой стенкой всегда встречаются в базальной части полипняков, тонкостенность можно рассматривать как признак юной стадии в развитии отдельного кораллита. Значи тельно сложнее, однако, объяснить неоднократное повторение тонкостенных отрезков в течение роста одного кораллита. Видимо, причины этого явле. ния кроются в общих осо. бенностях биологии кишечнополостных, о которых будет сказано ниже.

Совершенно иначе выглядит стенка кораллитов в том случае, если в кораллите развиты короткие септальные ребра или грубые короткие шипы с широким основанием. Их слиянием образуется стенка, очень напоминающая так наз. септотеку ругоз. Стенки здесь толщиной около $0,1-0,2$ мм и имеют в тангенциальном разрезе характерные пережимы (рис. 2, B (средняя часть); табл.I, фиг. 1 ; табл. IV, фиг. 3). Это обусловлено совпадением септальных образований на общей стенке двух смежных кораллитов. Однако аналогичную картину создают также многочисленные стенные и угловые поры, почти всегда закрытые сравнительнс толстыми поровыми пластинками, которые можно принять за тонкие отрезки стенок. Склеренхима при утолщенной стенке также тонкозернистая, но ее пятнистая окрашенность придает всей стенке трабекулярный облик. Срединный шов, как правило, незаметен. Местами в середине стенки прослеживаются мелкие светлые точки, интерпретированные нами как реликты межстенного шва, почти полностью исчезнувшего в процессе перекристаллизации вещества стенок. Но не исключено, что, на самом деле, в этих местах находились мелкие пустоты, в которых размешались какие-то комменсалисты или даже симбнонты (табл. IV, фиг. 3). Ангопоры с описанным строением стенки были выделены К. Триппом (Tripp, 1933) с о. Готланд как представители III группы Favosites hisingeri M.-Edw. et Н., а Б. Соколовым (1952) из Эстонии как особый вид Favosites multicarinatus Sok.

Наиболее изменчивую толщину $(0,1-0,4$ мм) стенка имеет при пышном развитии септальных образований - длинных шипиков или прерывистых, нередко шиповатых по краю ребер, возникших при слиянии оснований шипиков (рис. $2, C$ ). Стенка отдельного кораллита в случае силь. ного развития септальных образований почти неуловима. Она вырисовывается только при наличии межстенного шва, иногда наблюдаемого в виде светлой пунктирной линии (табл. IV, фиг. 4). Вертикальной зональности, выдержанной в пределах всей колонии, в распределении сильно утолщенных стенок не наблюдается, хотя эти утолщения могут повторяться в одном кораллите несколько раз. Зато заметна связь очень тол- 

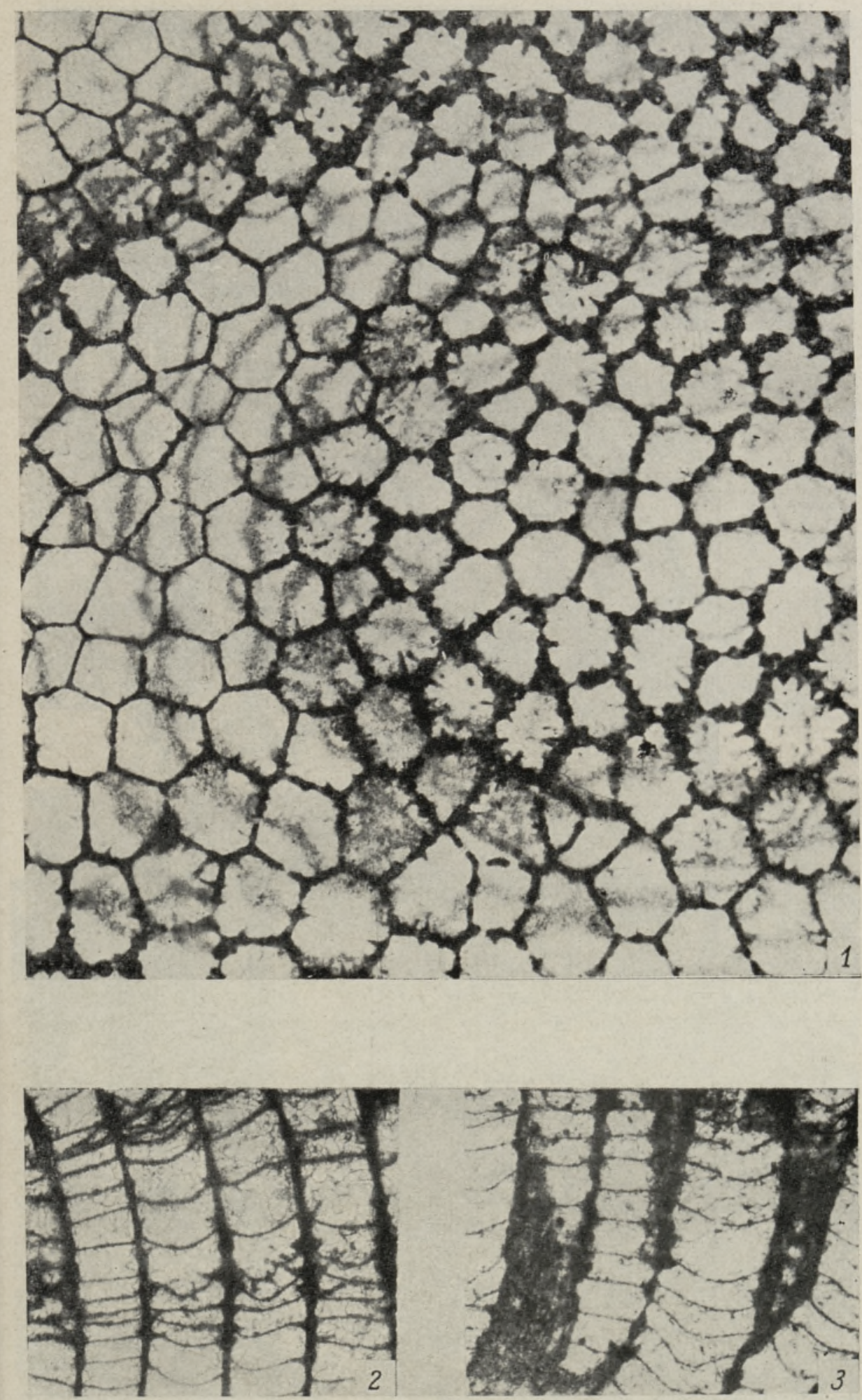

Фиг. 1, 2. Со 2301; о. Готланд, карьер цементной фабрики Висбю; нижние мергели Висбю. Поперечный и продольный разрезы. $\times 10$. 

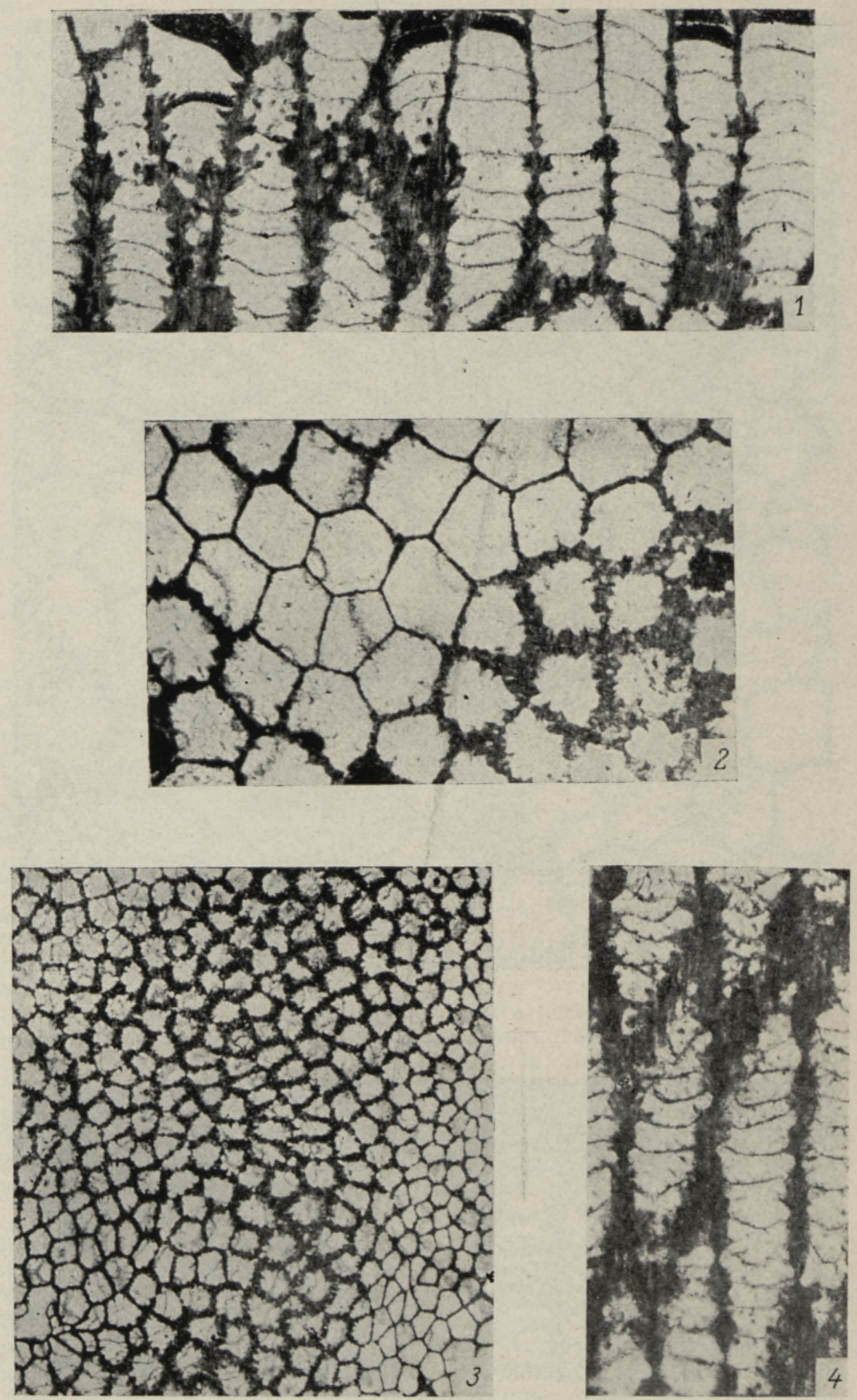

Фиг. 1, 2. Со 2305; о. Готланд, южнее аэропорта Висбю; верхние мергели Висбю. Продольный и поперечный разрезы показывают, что утолщение стенок происходит внезапно и может охватить не все грани одного кораллита. $\times 10$.

Фиг. 3, 4. Со 2304; о. Готланд, Корпклинт; верхние мергели Висбю. Поперечный $(\times 4)$ и продольный $(\times 10)$ разрезы. Расположение более крупных и толстостенных кораллитов совпадает с бугорками на поверхности полипняка, расположение более мелких - 

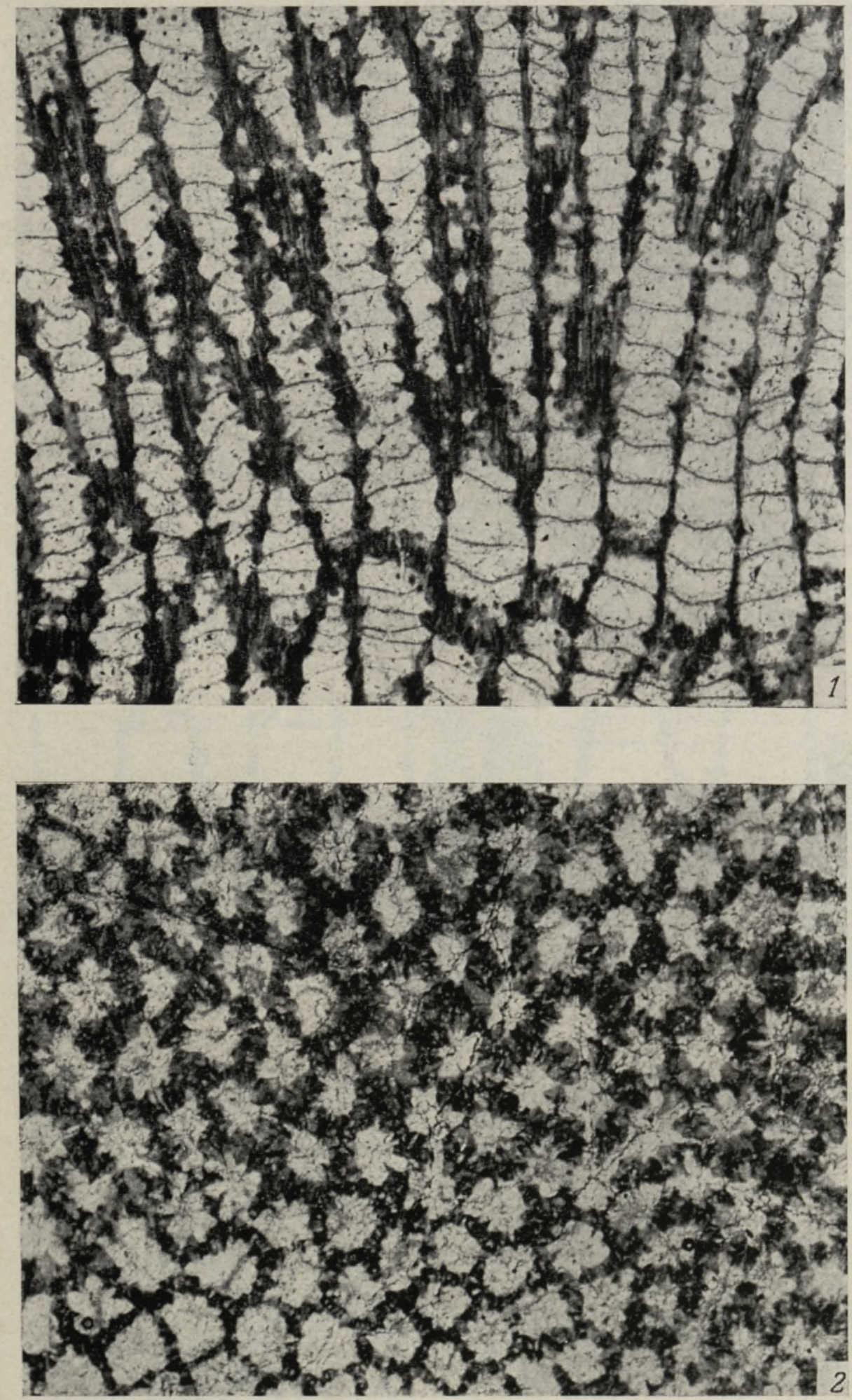

Фиг. 1, 2. Со 2306; о. Готланд, Хёгклинт; верхние мергели Висбю. $\times 10$.

Для экземпляра характерно пышное развитие септальных образований. Левая часть продольнсго разреза показывает, что септальные ребра возникли в результате слияния широких оснований шипиков. 

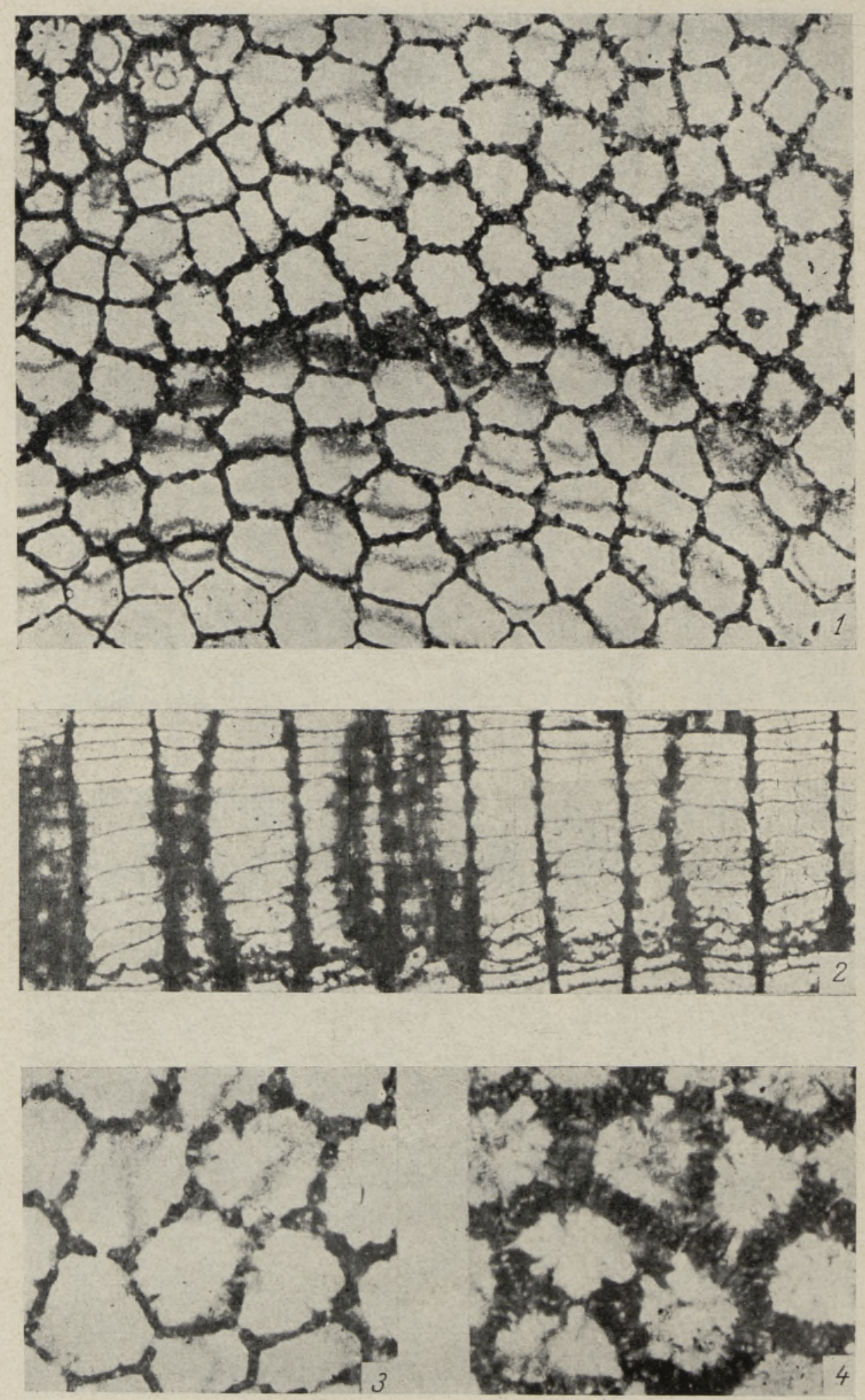

Фиг. 1-4. Со 2303; о. Готланд, карьер цементной фабрики Висбю; нижние мергели Висбю. $\times 10$ и 16 (фнг. 3,4).

Об́ращает на себя внимание вполне фавозитоидный продольный разрез, так как септальные ребра выражены весьма слабо. Поперечные разрезы большего увеличения показывают свойственную для рода пятнистую окрашенность и поперечные пережимы стенік. Межстенный шов или совершенно незаметен, или местами наблюдается в виде ряда мелких светлых точек. 
стостенных кораллитов с поднятыми участками поверхности полипняка (буграми, вздутиями). В таком случае горизонтальный переход от тонкостенных кораллитов к толстостенным может быть очень резким (табл. II, фиг. 2), хотя обычно он носит более постепенный характер (табл. I, фиг. 1, табл. IV, фиг. 1). Из сказанного следует, что усиленное развитие септальных образований и появление толстостенности не происходило в колонни одновременно и тем самым не представляло синхронную реакцню слагающих колонию отдельных особей на изменения внешней среды.

Если экологический фактор сказывал какое-то влиянне на развитне септального аппарата, то это влияние ограничивалось в определенные моменты времени только отдельными кораллитами. В пользу этого говорит небольшое количество толстостенных кораллитов в некоторых полипняках. Поэтому более правдоподобным будет допущение, что повторное изменение толщины стенок в кораллитах Angopora hisingeri отражает определенные возрастные этапы в жизни его коралловых полинов, - «цикличное омоложение и созревание одних и тех же зооидов», отмеченное Б. Преображенским (1967) в цилиндрических полипняках та булят. Этот процесс, не будучи одновременным во всех кораллитах, мог сопровождаться изменением интенсивности секреционной деятельности зоондов.

П оры у рассматриваемого вида расположены как на ребрах, так и на гранях, на последних - одним-тремя неправильными рядами. Преобладают два ряда стеннных пор. В поперечнике поры преимущественно равны $0,1-0,15$ м, , а расстояние между порами в ряду - $0,2-$ 0,6 мм. Кроме округлых пор, бывают и овальные, которых нередко больше, чем округлых. Большая ось овальных пор варьируется в интервале $0,15-0,22$ м. П. Поры толстостенных участков колонии напоминают в тангенциальных шлифах каналы (рис. $2, C$ ), нередко закрытые поровой пластинкой с обоих концов.

Д н и а - горизонтальные, слегка изгибающиеся, с интервалом 0,5-1,1 мм; между отдельными днищами расстояние может сокращаться до 0,3-0,15 мм. Уменьшение интервала между днищами совпадает с усиленным развитием септальных образований, но четкой зональности, свойственной раннесилурийским фавозитидам Прибалтики, не возникает.

Приведенная выше характеристика отдельных морфологических элементов позволяет суммировать типичные признаки Angopora hisingeri (Jones) в следующем диагнозе:

Полипняк неправильный, корковидный, с неровной, часто бугристой поверхностью. Кораллиты призматические, но при сильном утолщении стенок их пяти-шестигранный габитус исчезает. Преобладают кораллиты диаметром 1,2-1,6 мм. Стенки мелкозернистой микроструктуры, без видимого шва или с прерывистым швом; толщина стенки, зависящая от степени развития септального аппарата, колеблется в разных частях колонии от $0,04-0,1$ до 0,15-0,4 мм. Утолщение стенки сопровождается лятнистой окрашенностью скелетного вещества. Септальные образования представлены шипиками или ребрами (нередко прерывистыми), возникшими в результате слияния оснований шипиков. Количество рядов септ непостоянное. Поры угловые и стенные (1-3 ряда), округлые нли эллиптические. Диаметры округлых - $0,1-0,15$ мм, а малые и большие оси эллипсов состветственно - 0,1-0,15 и 0,15-0,22 мм. Днища горизонтальные, умеренно частые.

Геологическое и географическое распространение. Достоверные представители Angopora hisingeri встречены в коренном

5 ENSV TA Toimetised $\mathrm{K} * \mathrm{G}-11970$ 
залегании только в верхнем лландовери Скандинаво-Балтийской области: в нижних и верхних мергелях Висбю о. Готланд и в слоях $7 c \beta$ в Рингерике (Норвегия). В Әстонии они установлены в эрратическом материале (о. Сааремаа, берег моря у дер. Яани), который, вероятно, тоже позднелландоверийского возраста.

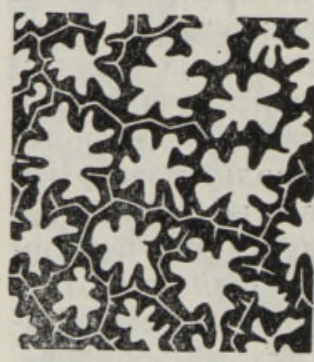

Т аксономическая позиция Angopora

Для определения соотношения ангопор с тециидами мы сравнивали Angopora hisingeri (Jones) с типовым видом рода Thecia - Thecia swinderniana

Рис. 3. Поперечный разрез кораллитов Thecia swinderniana (Goldf.). Со 1587 - Эстония, о. Сааремаа, Мыннусте, лудловский ярус, паадлаский горизонт. $\times 16$.

(Goldf.). Такое сравнение показало существование ряда отличительных черт, которые не позволяют не только отождествить роды Angopora и Thecia, но и отнести ангопор к тециидам вообще.

Қак видно из рис. 3, септы у Thecia swinderniana образуются как бы выгибанием всей стенки, так как межстенный шов, везде хорошо заметный, продолжается и в середине септ. У Angopora, как было показано выше, септальное ребро возникает в результате слияния оснований обыкновенных шипиков. Кроме того, у тециид количество септальных ребер в кораллите довольно постоянное - 6 или 12 , в то время как количество рядов шипиков у Angopora hisingeri вообще не обнаруживает постоянства. У тециид также отсутствуют имеющиеся у Angopora два типа пор угловые и стенные, не отмеченные в прежних описаниях. Этот признак, а также строение стенок и септального аппарата больше всего сближает ангопор с распространенными на том же стратиграфическом уровне представителями группы Mesofavosites obliquus (Sok.). На основании этсго сходства представляется целесообразным рассматривать ангопор как особую ветвь семейства Favositidae, взявшую свое начало, вероятнее всего, от Mesofavosites. Такой вывод близок к заключенню А. Стасинской (Stasinska, 1967). Разница заключается лишь в интерпретации ранга ангопорид. На наш взгляд, род Angopora должен войти в то же семейство, в которое входит родоначальный для него Mesofavosites. Это значит, что мы считаем более естественным рассматривать ангопорид в ранге подсемейства (Angoporinae Stasinska, 1967) в составе семейства Favositidae. При этом объем подсемейства принимаем равным объему семейства Angoporidae в понимании А. Стасинской, включившей в него роды Angopora н Kiaerites. По сравнению с Angopora сходство последнего рода, также позднелландоверийского возраста, с мезофавозитами более отдаленное. Зато между Angopora и Kiaerites принципиальных различий нет. Последний отличается, главным образом, ярче выраженной септотекой, состоящей более чем из 46 рядов тонких септальных шипиков. Остальные его огличия - бо́льший размер кораллитов и пор, бо́льшая толщина стенок - носят количественный характер и поэтому самостоятельность рода, на наш взгляд, еще нуждается в углубленном обосновании. 


\section{ЛИТЕРАТУРА}

Кл а а м н н Э. Р. 1964. Позднеордовикские и раннесилурийские Favositida Эстонии. Ин-т геол. АН ЭССР. Таллин.

П р еобр а же н с к и й Б. В. 1967. Значение зональных явлений в скелете табулятоморфных кораллов. Палеонт. ж., № 3.

С околов Б. С. 1952. Табуляты палеозоя Европейской части СССР. Ч. ІІІ. Силур Прибалтики. (Фавозитиды венлокского и лудловского ярусов). Тр. ВНИГРИ,, нов. сер., вып. 58. Л.-М.

С около в Б: С. 1955. Табуляты палеозоя Европейской части СССР. Введение. Общие вопросы систематики и истории развития табулят (с характеристикой морфологически близких групп). Тр. ВНИГРИ, нов. сер., вып. 85. Л.-М.

С околов Б. С. 1962. Подкласс Tabulata. Табуляты. В кн.; Основы палеонтологии. Губки, археоциаты, кишечнополостные, черви. М.

H 11 D., Stum m E. 1956. Tabulata. In: Treatise in Invertebrate Paleontology. Part F. Coelenterata. Geol. Soc. Am. and Univ. Kansas Press. Lawrence, Kansas. J on es O. A. 1930. A revision of some Palaeozoic Coral Genera and Species. Abstracts of Dissertations approved for the Ph. D., M. Sc. and M. Litt. Degrees in the University of Cambridge for the academical year 1928-1929.

Jones O. A. 1936. The Controlling Effect of Environment upon the Corallum itr Favosites; with a Revision of some Massive Species on this Basis. Ann. Mag. Nat. Hist. 17, No. 10.

L a ng W. D., S m it h H., Th o m a s H. D. 1940. Index of Palaeozoic Coral Genera. Brit. Mus. (Nat. Hist.). London.

St a s insk a A. 1967. Tabulata from Norway, Sweden and from the erratic boulders of Poland. Palaeontologia Polonica, No. 18, Warszawa.

Trip p K. 1933. Die Favositen Gotlands. Palaeontographica, 79, A. Stuttgart.

Ннститут геологии

Академии наук Эстонской ССР
Поступила в редакцию

$18 / \mathrm{XI} 1968$

\section{E. KLAAMANN}

\section{ANGOPORA HISINGERI (JONES) MUUTLIKKUS JA TAKSONOOMILINE ASEND}

Gotlandi saare ülemländouverist pärineva Angopora hisingeri (Jones) koralliitide seina ehituses (joon. 2) esineb eriti suuri erinevusi. Järeldatakse, et septaalaparaadi intensiivne arenemine ja sellest tingitud koralliitide seina paksenemine ei peegelda väliskeskkonna sesoonseid muutusi, vaid teatud küpsuse saabumist kolooniat moodustavate üksikindiviidide arenemises. Erinevuste pōhjal antakse Angopora hisingeri (Jones) täpsustatud diagnoos.

Peetakse vōimalikuks Angopora pōlvnemist perekonnast Mesofavosites, millele viitavad pooride analoogiline paiknevus ning sarnanevad jooned septaalaparaadi ehituses. Pannakse ette käsitada perekondi Angopora ja Kiaerites sugukonna Favositidae alamsugukonnana Angoporinae Stasinska, 1967.

\section{E. KLAAMANN}

\section{VERÄNDERLICHKEIT UND TAXONOMISCHE STELLUNG DER ANGOPORA HISINGERI (JONES)}

Die Bearbeitung neuer Versammlungen von Angopora hisingeri (Jones) - des Generotypus der Gattung Angopora - aus dem oberen Llandoverium der Insel Gotland hat eirie große Veränderlichkeit im Bau der Korallitenwände und des Septalapparats dieser Art festgestellt. Es wurde konstatiert, daß die Mauerdicke der Koralliten von der Wachstumsintensität der Septen abhängt (Abb. 2). Abschnitte mit gut entwickelten Septen wechseln dabei in jedem Korallit mit fast septenlosen Teilen ab. Da solche Wiederholung nicht gleichzeitig im ganzen Stock stattgefunden hat, ist wahrscheinlich, daB die periodischen Veränderungen in Mauerbreite und Entwicklung der Septen bei Angopora hisingeri nicht durch klimatische oder andere ökologische Faktoren bedingt sind, sondern ein Resultat einer zyklischen Entwicklung der Zooiden darstellen.

Die diagnostischen Merkmale von Angopora hisingeri werden in folgender Beschreibung summiert. 
Der Stock flach, mit kleinen Erhöhungen an seiner Oberfläche. Die Zellröhren fünfoder sechsseitig und besitzen vorwiegend einen Durchmesser von 1,2 bis $1,6 \mathrm{~mm}$. Die Mauerdicke, die von der Entwicklung der Septen abhăngt, beträgt in verschiedenen Teilen des Stocks von $0,04-0,1 \mathrm{~mm}$ bis $0,15-0,4 \mathrm{~mm}$. Mauerstruktur feinkörnig, bei starker Verdickung unregelmäßig gefärbt; Mittellinie unterbrochen oder fehlt ganz. Der Bau der extrem dicken Mauern weist eine bedeutende Ahnlichkeit mit sogenannten Septotheca der Tetrakorallen auf. Septalapparat besteht aus Dornen verschiedener Länge; infolge dez Zusammenschließens ihrer verhältnismäßig breiten basalen Teile werden ununterbrochene oder fragmentarische senkrechte Septen gebildet. Die Anzahl der Septenreihen in einem Korallit ist nicht konstant. Die Poren sind gleichzeitig auf den Mauern (1-3 Reihen) und an den Mauerkanten angeordnet. Sie sind rund oder leicht oval, entsprechend $0,1-0,15 \mathrm{~mm}$ oder $0,1-0,15 \times 0,15-0,22 \mathrm{~mm}$ im Durchmesser. Der Abstand der horizontalen Tabulae liegt zwischen 0,5 und $1,1 \mathrm{~mm}$.

Verbreitung. Ober-Llandoverium der Insel Gotland (Schweden) und RingerikeGebiet (Norwegen). In Estland ist bisher nur aus erratischem Material wahrscheinlich desselben Alters auf der NO-Küste der Insel Saaremaa bekannt.

Große Ahnlichkeit in der Anordnung der Poren und im Bau der Septaldornen läBt eine Verwandtschaft zwischen den Gattungen Angopora und Mesofavosites annehmen. Deshalb wird der Vorschlag gemacht, Angopora sowie auch die Gattung Kiaerites als eine Unterfamilie Angoporinae Stasinska, 1967 zur Familie Favositidae zu ordnen. Von der Giattung Thecia, mit welcher Angopora in der Literatur oft synonymisiert wurde, läßt die Gattung Angopora sich nach zwei Typen der Poren (auf den Mauern und Mauerkanten) und nach dem vorwiegend aus Dornen bestehenden Septalapparat unterscheiden. 